\title{
CHROMATIC FACTORS OF BRIGHTNESS MATCHING BETWEEN COMPUTER DISPLAY AND AMBIENT ILLUMINATION
}

\author{
Nagy, B.V. ${ }^{1,2}$, Gilman, S. ${ }^{2}$, Ventura, D.F.2 \\ ${ }^{1}$ Department of Mechatronics, Optics and Engineering Informatics, Budapest University of Technology \\ and Economics, HUNGARY ${ }^{2}$ Vision Laboratory, Institute of Psychology, University of São Paulo, \\ BRAZIL \\ nagyb@mogi.bme.hu
}

DOI 10.25039/x44.2017.PO11

\begin{abstract}
The aim of the current study was to analyse the effect of ambient illumination on brightness matching on a computer display. A human size light booth, equipped with LED and fluorescent light sources, was constructed to create uniform ambient illumination for visual tests with similar chromatic characteristics. The participants adjusted the luminance of a uniform chromatic stimulus presented on a display to be equal to that of the ambient. The recorded display luminance values show large variability among the test participants and differences between the used illuminations depending on the stimulus colour. In case of white stimulus, the matched brightness values were similar while in the case of the yellow stimulus the LED ambient appeared brighter. One conclusion is that when matching a display to its ambient in terms of brightness, observers may demonstrate less variability when the ambient colour is closer to the display colour.
\end{abstract}

Keywords: brightness matching, ambient illumination, display, visual task

\section{Introduction}

Several groups have studied brightness perception issues lately, indicating many aspects starting with the well-known differences of brightness from the measured luminance values (Alman, 1977; Booker, 1978; Berman, 1990). The effects of different parameters such as stimulus temporal and spatial arrangement, size, visual angle of the lighting fields and visual targets, spectral power distribution and chromatic attributes, mean luminance level, among others have been considered. (Oguichi, 1999; Houser, 2003; Fotios, 2001, 2006, 2011). The recent report of the CIE TC1-80 (CIE 2014) summarizes well the works done and the considerations for brightness perception testing and shall improve our knowledge on spatial design of the illumination ambient. As the human visual system primarily processes brightness and chromatic information in separate neural channels with both channels contributing to brightness perception up to certain levels (Yaguchi, 1983; Shevell, 2001; Lee, 2010), one needs to consider these aspects when testing perceived brightness, although the interaction of these neural channels, especially for brightness perception is not very well understood yet. Our laboratory study on human brightness perception takes into account the differences in spectral power distribution of the illumination (Stephens, 2005) while keeping all measured parameters constant in order to analyze the chromatic and brightness matching abilities using ambient illumination and visual targets on a computer display.

\section{Methodology}

A human size light booth (Fig.1) was constructed to create uniform ambient illumination (Nagy, 2013, 2015) for the psychophysical visual tests. The booth was equipped with LED and fluorescent light sources. For the current project the luminance of the ambient was adjusted to $\mathrm{L}=90.4 \pm 9.7 \mathrm{~cd} / \mathrm{m}^{2}$ for the $\mathrm{LED}$ and $\mathrm{L}=89.3 \pm 13.7 \mathrm{~cd} / \mathrm{m}^{2}$ for the $\mathrm{FL}$ illumination as measured with a Konica Minolta CS-1000 spectroradiometer in a 4-by-4 grid within the booth. The correlated colour temperature, calculated from the spectral radiance was also similar for both illumination conditions (2702K for the LED and $2653 \mathrm{~K}$ for the $\mathrm{FL}$ ). 

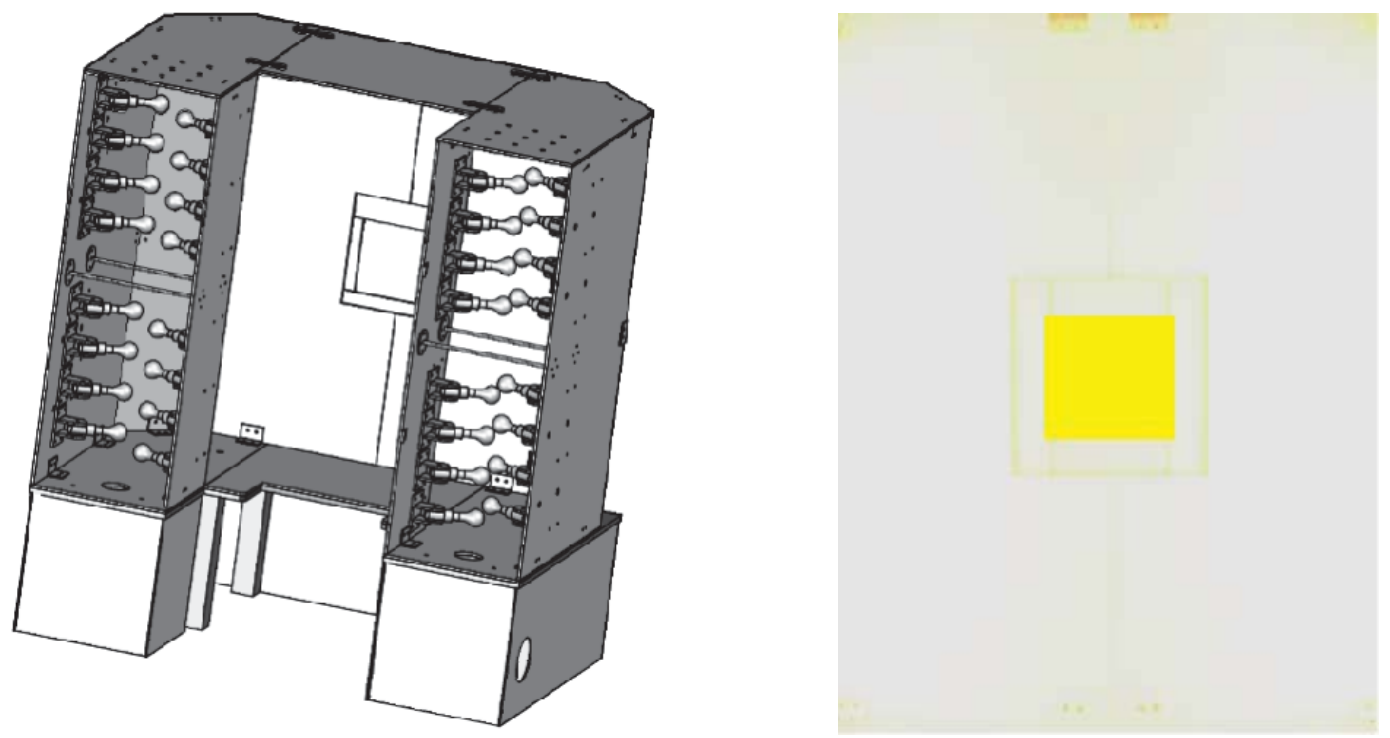

Figure 1 - Schematic view of the test ambient with the light sources (left) and as viewed by the test subjects (right) with the yellow square indicating the stimulus on the display

The human tests were designed on a calibrated computer display positioned behind the light booth and viewed through and observation window. The display was placed outside the light booth to avoid screen reflections and the test were applied as full screen uniform stimuli for both luminance and chromaticity. Fifteen healthy participants with no colour vision problems (verified with the Cambridge Colour tri-vector test) took part in the tests. Their task was to immerse in the illumination ambient and, after 10 minutes adaptation, adjust the luminance of the uniform stimulus presented on the computer display for the its brightness to be equal to that of the ambient. The colour stimuli applied were yellow $\left(u^{\prime}, v^{\prime}=0.202,0.542\right)$ and white $\left(u^{\prime}, v^{\prime}=0.192,0.441\right)$ within $3^{\circ}$ and $6^{\circ}$ of fields of view. The recorded values were those of the adjusted display luminance levels matching the ambient illumination. The participants were instructed to fixate on the center of the display when matching the luminance with the ambient.

A further visual test (red-green HMP - Heterochromatic Modulation Photometry; Kremers, 2003) was applied to estimate the $L$ and $M$ cone ratio of the observers in order to see if it correlates with the matching brightness between the illumination conditions. This has been done on the calibrated display as well, however in the dark, without the ambient illumination.

\section{Results}

Brightness matching results on the display with the ambient illumination had large variability among the test participants, with the larger $\left(6^{\circ}\right)$ FOV having higher adjusted values (Fig.2) than the smaller FOV $\left(3^{\circ}\right)$ for both ambient illuminants. At the same time, individual adjustments were well correlated among the test participants for the two field sizes $(R>0.71)$.

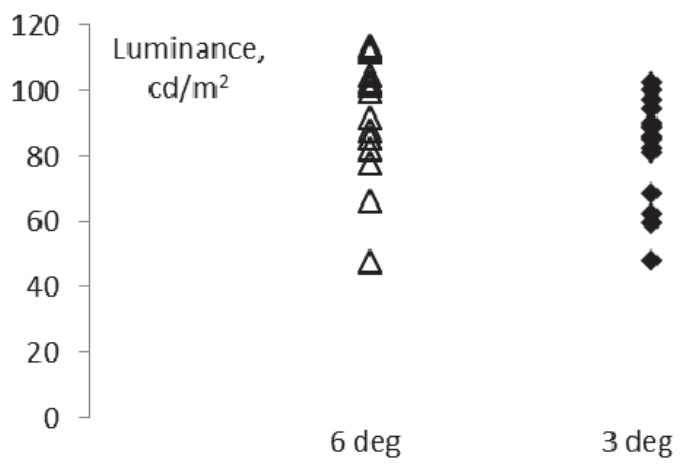

Figure 2 - Adjusted matching luminance values for the FL27 ambient at different visual field sizes 
We have found differences between the two ambient illuminants depending on the stimuli used. In case of the white stimulus (Fig. 3 bottom), the matched brightness values under the two ambient illuminants were similar (seven participants out of fifteen gave higher luminance adjustments for the LED ambient). On the other hand, in the case of the yellow stimulus the LED ambient appeared to be slightly brighter for the majority of the participants (Fig.3 top).
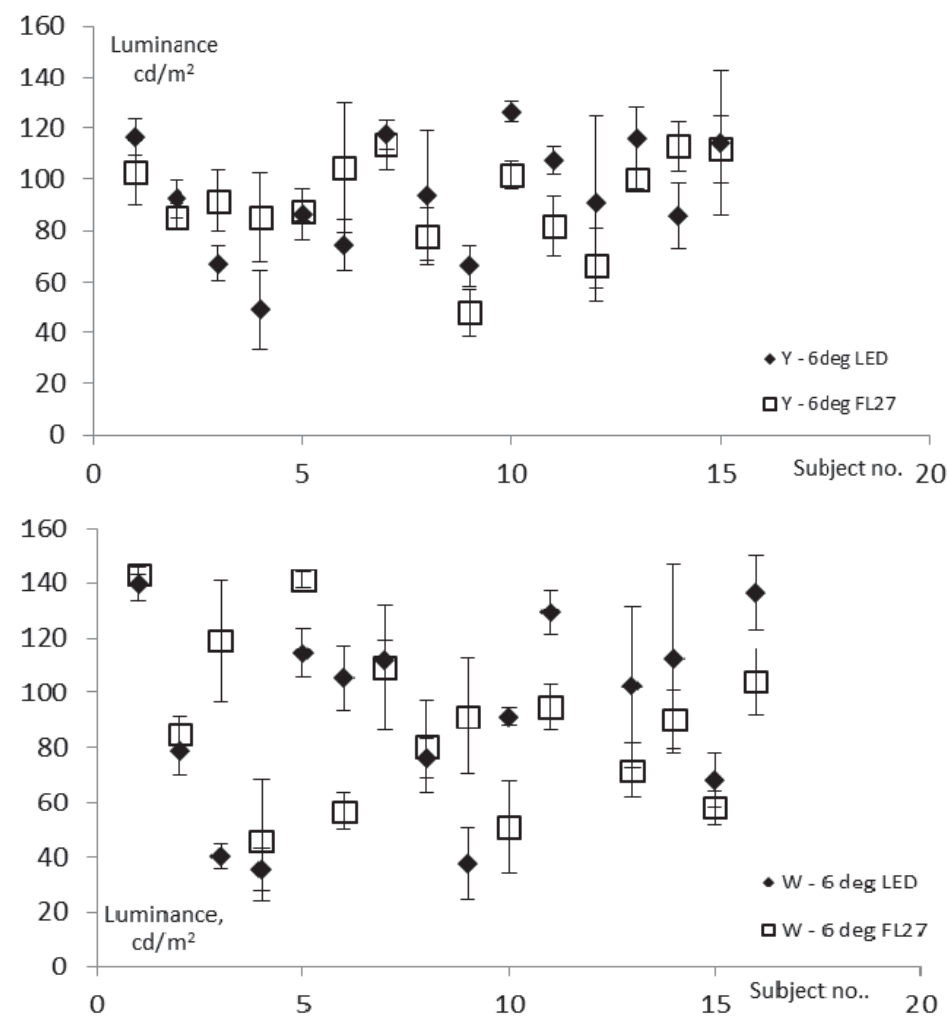

Figure 3 - Adjusted matching luminance values for the yellow (top) and white (bottom) stimuli

The correlation for the matched luminance values between the two ambient illuminations was relatively high $(R>0.69)$ and significant. We did not find correlation between the brightness matching results between the two target stimuli. The HMP results showed lower and insignificant correlation with the brightness matches for the yellow stimulus, and no correlation in case of the white stimulus.

\section{Conclusions}

The larger individual variations for the white stimulation compared to the yellow show the general difficulty to adjust for brightness matching between chromatically different illuminations. Thus, when matching a display to its ambient in terms of brightness, observers may demonstrate less variability when the ambient apparent colour, although spectrally distant, is closer to the target's colour.

Brightness matching for both stimulations correlated well under both illumination types meaning that there was a significant contribution of individual brightness perception to the test results. This indicates little interference of adaptation SPD to brightness matching as that was clearly different for the two ambient illuminations while their apparent colours were practically equal.

The individual differences in brightness matching for the white and yellow stimuli might suggest the independent neural processing of brightness from colour in colour normal individuals.

The correlation, although not significant possibly due to the relatively low number of tested individuals, found between the L/M cone ratio for the yellow stimulation indicates, that while 
matching colours with a similar ambient, the role of the cone ratio might be more effective than in the case of larger chromatic differences.

\section{References}

Alman DH. 1977. Errors of the standard photometric system when measuring the brightness of general illumination light sources. Journal of the Illuminating Engineering Society: 5562.

Berman SM, Jewett DL, Fein G, Saika G \& Ashford F. 1990. Photopic luminance does not always predict perceived room brightness, Lighting Research \& Technology, 22(1): 37-41

Booker RL. 1978. Luminance-brightness comparisons of LED alpha-numeric sources at suprathreshold levels. Journal of the Optical Society of America 68(7): 949-952.

CIE 2014, CIE 212:2014 Guidance Towards Best Practice In Psychophysical Procedures Used When Measuring Relative Spatial Brightness. Vienna: CIE.

Fotios SA. 2001. Lamp colour properties and apparent brightness: a review. Lighting Research and Technology 33(3): 163-181.

Fotios SA, 2006. The Effect Of Chromatic Adaptation Upon The Relationship Between Lamp Spectrum And Brightness At Photopic Levels, Lighting Research \& Technology, 38(1); 317

Fotios SA \& Cheal C. 2011. Brightness Matching With Visual Fields Of Different Types, Lighting Research \& Technology, 43(1): 73-85

Houser KW, Tiller DK. 2003. Measuring the subjective response to interior lighting: paired comparisons and semantic differential scaling. Lighting Research \& Technology 35(3): 183-198.

Kremers, J, Stepien, MW, Scholl, HPN, Saito, C 2003. Cone selective adaptation influences $\mathrm{L}-$ and $\mathrm{M}$-cone driven signals in electroretinography and psychophysics. Journal of Vision (2003) 3, 146-160

Lee, B. B., Martin, P. R., \& Grunert, U. 2010. Retinal connectivity and primate vision. Progress in Retinal and Eye Research, 29, 622-639.

Nagy, B.V., Barboni, M.T.S., Oliveira, J.G., Ventura, D.F. 2013. The effect of ambient illumination spectrum on visual performance. In: Proceedings of the CIE Centenary conference, Paris. Viena, Austria: CIE, p. 625-630.

Nagy, B.V.; Strabelli, P.; Horn, M. T.; Duque-Chica, G. L.; Ventura, D. F. 2015. Influence of blue and amber ambient illumination on cognitive performance. In: 28th CIE SESSION, 2015, Manchester. Proceedings of 28th CIE SESSION, Viena, Austria: CIE, p. 625-630.

Oguichi Y, Ishida T \& Hokoi S. 1999. Quantitative estimation of environmental brightness based on its perceptual composition, 24th Session of the CIE, vol. 1(1), 92-96

Shevell SK. 2001. The time course of chromatic adaptation. Color Research \& Application, Supplement 26: S170-S173

Stephens N \& Bolander A, 2005. Factors in the perception of brightness for LED and incandescent lamps, , SAE Transactions vol 114, part 6, pp.908-920

Yaguchi H, Ikeda M. 1983. Contribution of opponent-colour channels to brightness. in Mollon JD \& Sharpe LT, Colour Vision: Physiology \& Psychophysics. Academic Press Ltd; London. 